EPiC Series in Computing
Volume 78, 2021, Pages 115-125
Proceedings of the European Univer-
sity Information Systems Conference 2021

\title{
Improvement of Teaching and Learning Experience by Online Course Diary Tool: Qualitative Exploration of Teachers' Perspective
}

\author{
Ville Kivimäki $^{1 *}$, Jani Romanoff ${ }^{2}$ and Heikki Remes ${ }^{2}$ \\ ${ }^{1}$ University of Helsinki, Finland \\ ${ }^{2}$ Aalto University, Finland \\ Ville.Kivimaki@helsinki.fi, Jani.Romanoff@aalto.fi, \\ Heikki.Remes@aalto.fi
}

\begin{abstract}
Due to the rapid shift to online learning, it has become increasingly difficult for teachers to monitor students' learning experiences. This paper analyzes teachers' experiences with an online tool for monitoring students' metacognitive states during the learning process. Through an open-ended questionnaire, we collected teachers' aims for starting to use the tool and experienced benefits. Our results show that teachers use this tool to understand the learning status of students in greater depth and to adjust their teaching according to feedback collected during the course. Moreover, teachers reported receiving better quality summative course feedback after starting to use the tool.
\end{abstract}

\section{Introduction}

The connection between teacher and student has been challenged by the rapidly imposed mode of online learning that has continued for over a year now. In the first phase of the shift to nearly all-online learning, the change from technology-enhanced face-to-face teaching to fully online teaching was done basically overnight. This has been a significant challenge for higher education since, for instance, blended learning together with face-to-face teaching activities has been shown to yield better academic achievement than fully online teaching.

In online teaching, efficient use of teaching technology is a crucial issue. In their meta-analysis, Borokhovski et al. (2016), found a low but significant positive effect in learning outcomes with technology use (Hedges' $\mathrm{g}=0.27$, where $\mathrm{k}=879, \mathrm{p}<.01$ ). They compared the effects of different

* https://orcid.org/0000-0003-4939-7400 
Improvement of Teaching and Learning Experience by Online Course Diary Tool: ... Kivimaki et al.

types of conceptual frameworks: collaborative learning, feedback strategies, information processing, multimedia theory and problem-based learning. The highest effect $(g=0.75)$ was found in feedback strategies. In the wider view, Borokhovski et al (2016) end up promoting technologies that support students' cognitive processes, rather than presentational support tools. Borokhovski et al. (2016) further note that technology alone is not the solution. This is in line with a study by Geraldine, Schalk, Rooney and Lang (2021), which showed that students prefer their data to improve teaching quality first and improve course design second.

In the ongoing COVID-19 outbreak and due to increasing digitalization of our online education, we should have several methods for monitoring teaching and learning activities, as suggested by Alrefaie, Hassanien and Al-Hayani (2020). The challenge we face now is the need to find effective pedagogical methods and design instructional activities so that they support students' cognitive learning processes and facilitate meaningful interactions between online learning and computer-aided instruction. In addition, we should be aware of the emotional climate of the course. The emotional climate is important, as has been demonstrated in an abundance of studies. In fact, in their meta-analysis of 99 studies, Roorda et al. (2011) confirmed significant positive association between teacher-student relationship and school engagement and achievement. Further, they found that negative teacher-student relationship and poor achievement seem to strengthen the association like a vicious cycle (Roorda et al., 2011).

To tackle these challenges, we developed an online feedback and learning reflection tool, Course Diaries. This tool aims to correspond to a student's needs and goals during the course through adaptive learning and teaching. In addition, due to the structured design, the data can service course development over years and inform large-scale development at the level of e.g. degree program. In this study, we will explore teachers' experiences using the tool as the teachers are in a key role in adopting new technologies to enhance learning. This has been demonstrated in recent studies, as we will discuss later.

\subsection{Diaries in teaching and learning and the Course Diaries}

There are several activities closely related to the Course Diaries tool. First, perhaps the most traditional use of course diaries are reports written by teachers or students documenting what happened during the course. These types of documents are a valuable source of information for course development and the annual monitoring of student performance for faculty and administration in a wider development context, and they are also valued as new teachers' induction material (Gronseth, 1999). Second, student-facing learning diaries are sometimes referred to as course diaries. These aim to collect e.g. key course activities, links, further reading, key concepts and main takeaways from the course content, typically in a personal and reflective way (Allison, 1998). The third way of using course diaries is typically related to qualitative research, where a sample of students write diaries of their own to keep track of their learning activities (Bartlett \& Milligan, 2015). This information can be used to analyze e.g. behavioral changes over time or to compare groups with different learning techniques. Further, digital learning diaries that have structured components, such as Likert scales, instead of blank diary pages can generate time-series data and offer quantitative data for analysis (Klug et al., 2011).

In this paper, Course Diaries refers to a learning analytics tool that was thus named by students. Course Diaries is a tool that combines student- and teacher-facing tools and has value in collecting metacognitive data for research purposes (Kivimäki et al., 2019). From a student's perspective, the tool constitutes a structured learning diary that promotes metacognitive thinking through individual reflection on course content. This data is aggregated by the underlying IT system and shared on a group level with all course students who have sent their own responses and with the course teachers. Teachers can monitor how their students react to the course content, typically on a weekly basis, and adjust their teaching methods and strategies accordingly. The focus of this paper is to examine how teachers planned to use this application and how it affected their teaching or students' learning.

The first concept of the Course Diaries tool was presented at the EUNIS congress 2018 by Kivimäki et al. (2018). At that time, the conceptual work was referred to as Dynamic Feedback System (DFS). 
Improvement of Teaching and Learning Experience by Online Course Diary Tool: ... Kivimaki et al.

The concept was further developed from a theoretical perspective by Kivimäki et al. (2019), and the effects of the tool on self-regulation and school engagement were studied by Pesonen et al. (2020). Today, the tool is available for the Moodle digital learning platform as well as Android and iOS mobile platforms. This two-interface system was selected based on the usability study by Tiina Hahto (2020).

\subsection{Research questions}

Earlier research around Course Diaries has focused on student perspectives and learning theories. In this paper, we explore teachers' views on a tool designed to support cognitive learning processes through metacognition. Virtual environments challenge teachers to stay on top of their course's emotional climate. This is even more topical now during the COVID-19 pandemic, when the well-being of students is of great concern to teachers and educational institutions. Earlier research suggests positive effects with feedback activities aimed to support students' cognitive processes (Borokhovski et al., 2016). These types of higher design approaches can be demanding for teachers. In fact, several studies have concluded that in order to yield measurable changes in students' metacognitive skills, the use of a tool should be accompanied with proper metacognition training (Broadbent et al., 2020; Dignath-van Ewijk et al., 2015). Therefore, it is important to study teachers' reactions to using such a tool.

In this study, we are exporing teacher's experiences using the Course Diaries tool on their courses to inform higher education teaching and learning designers with use cases. Our research focuses on studying the following four dimensions: (1) What goals did the teachers want to achieve by using Course Diaries; (2) What kind of changes did teachers experience while using Course Diaries as a part of their instructional design; (3) How did the use of Course Diaries effect regular course feedback collection; and (4), in which situations teachers would recommend this type of tool to be used? Through these questions, we explore the ways the tool has been used and study the tool's perceived potential.

\section{Methods}

\subsection{Course Diaries - the tool}

The tool lists a student's courses and their intended learning outcomes as simplified course topics. On each topic, a student can assess their learning experience weekly through three fixed-scale items and three open-response items: competence (1), difficulty (2), feeling (3), expectations (4), notes (5) and reflection; see Figure 1 for a visual representation of the numbered items.
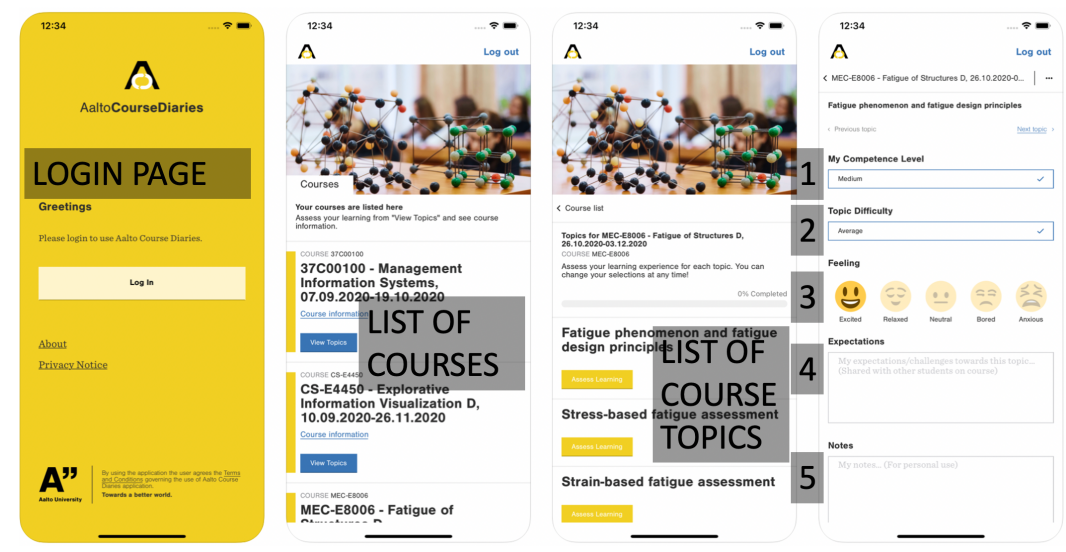

Figure 1: Student's mobile app UI 
Improvement of Teaching and Learning Experience by Online Course Diary Tool: ... Kivimaki et al.

Group-level aggregated data is visualized in the Moodle application (Figure 2) for the teachers of the course. In addition, students can see a similar summary view if they themselves have also submitted a response on that course topic. Students can submit their own responses either through the mobile application or the activity plugin found on the course page within Moodle. These user interfaces can be used simultaneously. The summary view with group-level data visualization is only available through the Moodle user interface. Teachers set up the plugin through Moodle's add activity function, at which point a mobile version is automatically made available for the students enrolled on the course. A systemlevel overview of the two student interfaces and teacher's interface is described in Figure 3.

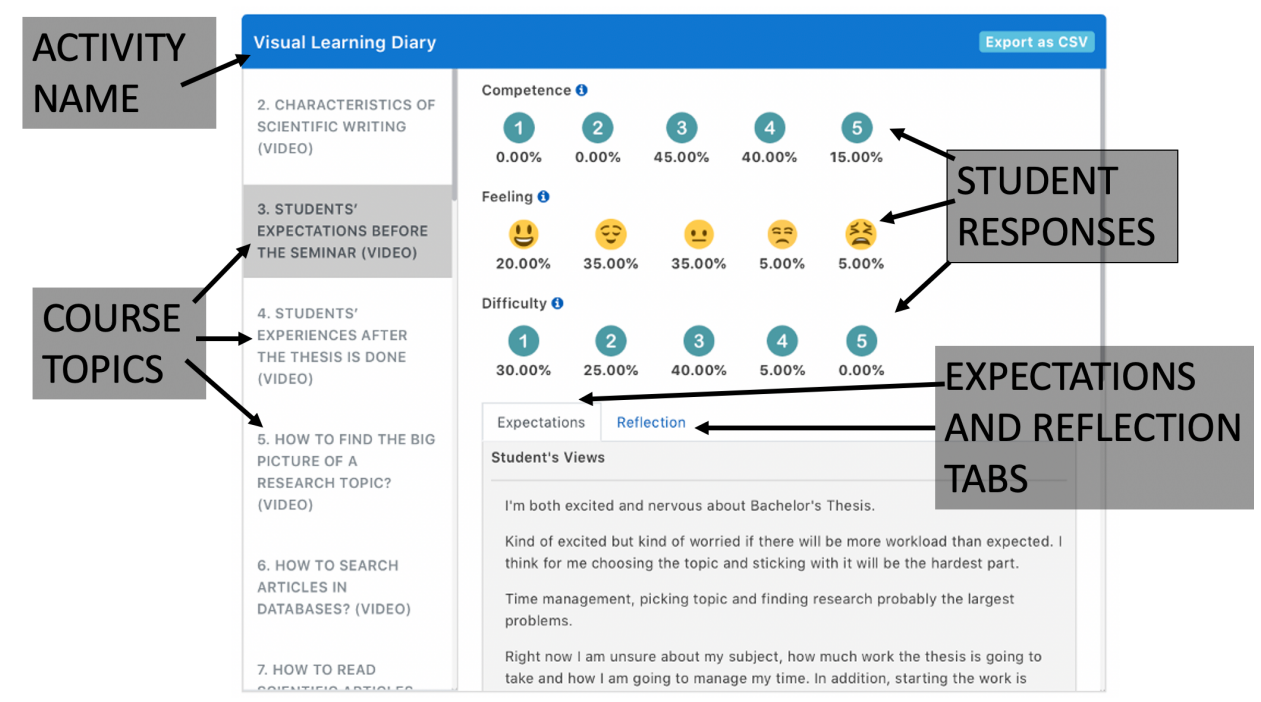

Figure 2: Teacher's report view in Moodle

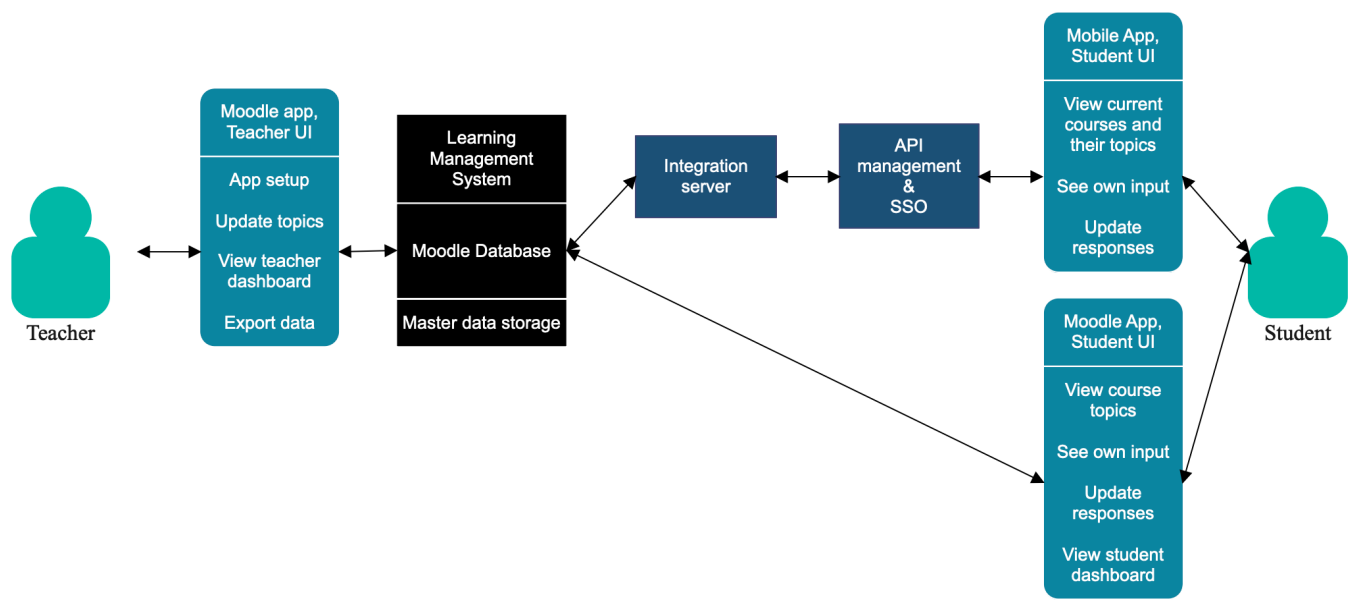

Figure 3: General overview of dataflows for teacher and student UI 
Improvement of Teaching and Learning Experience by Online Course Diary Tool: ... Kivimaki et al.

\subsection{Questionnaire}

To track teachers' views on Course Diaries, we created an online questionnaire with four openended questions. All of these are reported in this study: goals for the use of the CD tool, observed changes during the course, effects on regular course feedback after the course, and the teacher's views on which type of courses they would recommend using this type of application. The questionnaire was designed to give teachers an opportunity to give their answers without fear of being identified. Thus, we did not ask specific questions on course design or content to avoid teachers being identified. In addition, we used an online questionnaire solution where answers were collected completely anonymously. In the invitation letter, we underlined the fact that the questionnaire is completely anonymous to avoid teachers giving too optimistic answers.

\subsection{Analysis}

Our methodological approach is based on grounded theory (Glaser \& Strauss, 1967). Based on grounded theory principles, we prepared the data for qualitative analysis by creating categories based on our observations from the data and coded the answers into these categories accordingly. This method was used to create categories from the answers to the first two questions: the teacher's goals and observed changes. The third dimension, the effect on the summative regular course feedback, was operationalized to distinguish the sentiment: negative, neutral and positive views. Here, we further elaborated the content with examples. To analyze the fourth dimension, we operationalized the levels of technology use into categories used by Borokhovski et al. (2016): cognitive support (CS), presentational support (PS), communication support, and mixture of CS and PS. Based on the literature the latter combination of CS and PS was expected to be the most promising combination.

\section{Results and analysis}

This research on Course Diaries' utilization covers roughly 40 courses instructed by twelve different $(\mathrm{N}=12)$ teachers and attended by roughly 2,000 students. A web link to the questionnaire was sent to all teachers, who had been used the tool at the time of this study. Answers were collected for one week. Seven teachers participated, which corresponds to a $58 \%$ answer rate. All participants answered all four questions on the questionnaire. All answers were of good quality and consisted of several sentences and contained several comments and viewpoints.

\subsection{Teacher's goals}

Based on our findings, Course Diaries was mainly adopted as a part of instructional design to monitor students' learning experiences and to help a teacher prepare for their teaching activities (Table 1). Also, two teachers reported aims to promote deeper learning.

These results show variety in planned use cases. Teachers wanted to know how their students are learning. On the other hand, they had been looking for a tool to help them be better prepared for teaching activities. Some teachers expected the tool to foster possibilities for deeper learning. 
Improvement of Teaching and Learning Experience by Online Course Diary Tool: ... Kivimaki et al.

Table 1: Teacher's goals

\begin{tabular}{|c|c|c|}
\hline Category & Count & Example and coding criteria \\
\hline $\begin{array}{l}\text { Student } \\
\text { monitoring }\end{array}$ & 5 & $\begin{array}{r}\text { Teacher aims to monitor students to know how they are doing: } \\
\text { I wanted to know what's happening on my course students } \\
\text { heads. I think it's important to get some kind of response } \\
\text { during the course from students. Do they think they are } \\
\text { learning or not? } \\
\text { Distinctive words: know, real-time, tracking }\end{array}$ \\
\hline $\begin{array}{l}\text { Preparing for } \\
\text { teaching }\end{array}$ & 4 & $\begin{array}{l}\text { Teacher aims to use the data for preparing better in teaching } \\
\text { activities: }\end{array}$ \\
\hline & & $\begin{array}{r}\text { To know students' expectations and immediate feedback } \\
\text { already during the course, in order to take them into account } \\
\text { during the implementation. } \\
\text { Distinctive words: prepare, improvement, implementation }\end{array}$ \\
\hline $\begin{array}{l}\text { Promoting } \\
\text { deeper } \\
\text { learning }\end{array}$ & 2 & $\begin{array}{r}\text { Teacher aims to promote deeper learning on his/her course: } \\
\text { I wanted to improve the deep approach learning in my } \\
\text { course. The course goes through lots of different topics and I } \\
\text { hope that students would learn to understand them, not just } \\
\text { to "repeat a phrase explaining them". } \\
\text { Distinctive words: deep, comprehensive. }\end{array}$ \\
\hline
\end{tabular}

\subsection{Changes observed by teachers}

Teachers observed four types of changes in their courses (Table 2). Through deeper insights on what students think about course topics, teachers reported adapting course contents during the course. Two teachers reported increased thinking about their teaching, i.e., the teacher's metacognition. One reported noticing changes in students' metacognition.

Observed changes were aligned with the goals the teachers had set for using the tool. Namely, adapting of course content, insights and student's thinking are well aligned with the goals. However, teachers' metacognition seems to be a new emerging finding related to predefined goals. No respondent had raised this as a goal for using the tool. 
Improvement of Teaching and Learning Experience by Online Course Diary Tool: ... Kivimaki et al.

Table 2: Observed changes

\begin{tabular}{|c|c|c|}
\hline Category & Count & Example and coding criteria \\
\hline $\begin{array}{l}\text { Adapted course } \\
\text { content }\end{array}$ & 4 & $\begin{array}{l}\text { Teacher reports changes on his/her course: } \\
\text { I was able to respond to the issues brought up in the } \\
\text { Course diaries via announcements during the course. I } \\
\text { was also able to implement some of the ideas posed by } \\
\text { students during the course (e.g. what kind of alternative } \\
\text { tasks could be made instead of the final exam). } \\
\text { Distinctive words: tune, contents, re-visit, implement }\end{array}$ \\
\hline Insights & 3 & $\begin{array}{r}\text { Teacher reports getting better insights on course situation: } \\
\text { Especially the "emotions" part proved extremely useful in } \\
\text { this as I was also able to show students that they are not } \\
\text { alone in this feeling. } \\
\text { Distinctive words: see, emotions }\end{array}$ \\
\hline $\begin{array}{l}\text { Teacher's } \\
\text { metacognition }\end{array}$ & 2 & $\begin{array}{r}\text { Teacher reports changes in his/her own thinking as a teacher: } \\
\text { I think it made me thinking more about my own teaching. } \\
\text { Distinctive word: teaching }\end{array}$ \\
\hline $\begin{array}{l}\text { Student's } \\
\text { thinking }\end{array}$ & 1 & $\begin{array}{r}\text { Teacher reports changes in student behavior: } \\
\text { Students increase their self-awareness and have a } \\
\text { conscious relation with the study materials (comparing to } \\
\text { just gliding through without any second thought at all). } \\
\text { Distinctive word: self-awareness }\end{array}$ \\
\hline
\end{tabular}

\subsection{Effect on summative course feedback}

Regular course feedback is collected after the course and is compulsory for all courses. We asked in the questionnaire about teacher-observed effects on regular course feedback. These answers were first categorized based on the teacher's reported sentiment (Table 3) and then studied in further detail.

Table 3: Reported positivity / negativity related to regular course feedback

\begin{tabular}{lrr}
\hline Category & Count & Coding criteria \\
\hline Positive effect & 4 & Teacher reports getting better course feedback \\
Extremely positive & 2 & Teacher suggest the system to be taken into a wider use \\
No effects & 1 & Teacher reports no changes to regular feedback \\
\hline
\end{tabular}

In their responses, teachers reported having experienced mainly positive effects.

I think it impacted positively the course feedback cause I addressed problems earlier, without waiting for the end of course feedback.

[--] In general in regular course feedback students did also state that they were happy about the deep level of feedback they could provide, and that they saw it had a real effect.

Two teachers mentioned Course Diaries as a part of a larger feedback system.

Regular course feedback aims yearly based course development, while Course Diaries enable teacher to provide extended teaching in order to support better personalized learning.

One teacher reported no changes. The result is very optimistic, as no one reported experiencing worse summative feedback or reported a decline in the summative course feedback answer rate. 
Improvement of Teaching and Learning Experience by Online Course Diary Tool: ... Kivimaki et al.

\subsection{Teachers' recommendations for future use}

The fourth and final question was designed to gather the cases in which teachers would recommend Course Diaries to be used. Based on the teachers' answers, we divided each teacher's answer into levels of technology use categories (see Borokhovski et al., 2016).

Table 4: Technology use suggestions interpreted from teachers' answers

\begin{tabular}{lrrrr}
\hline Teacher & $\begin{array}{r}\text { Cognitive } \\
\text { Support (CS) }\end{array}$ & $\begin{array}{r}\text { Presentational Support } \\
\text { (PS) }\end{array}$ & $\begin{array}{r}\text { Communication } \\
\text { Support }\end{array}$ & $\begin{array}{r}\text { Mixture (CS } \\
\text { plus PS) }\end{array}$ \\
\hline 1 & $\mathrm{X}$ & & & \\
2 & $\mathrm{X}$ & $\mathrm{X}$ & $\mathrm{X}$ & $\mathrm{X}$ \\
3 & $\mathrm{X}$ & $\mathrm{X}$ & & $\mathrm{X}$ \\
4 & $\mathrm{X}$ & & & \\
5 & $\mathrm{X}$ & & $\mathrm{X}$ & \\
6 & & $\mathrm{X}$ & $\mathrm{X}$ & \\
7 & & & & \\
\hline
\end{tabular}

In cognitive support, teachers think about themselves and/or students benefiting from e.g. a lighter cognitive load. In the following example, the teacher clearly reflects with the COVID-19 situation:

This is a great tool for situations where you want to know what's happening. Getting better prepared for the lectures. This really suits to the current situation where you don't meet your students face to face. You get some kind of grip of what's going on and then you can think how to react to that.

Cognitive support for student is reflected by the following teacher:

Any courses the contents of which have clear topics or themes; courses that contain a challenging element and you want to engage your students to perform to the best of their abilities and also take responsibility of their own learning.

This teacher describes the presentational support power he sees on the tool:

[--] When the teacher is able to divide the course content into certain "blocks", which makes it easier to ask expectations and feedback about them. [--]

Communication support is described in the following expert:

[--] Also, in case you need feedback from various course "ingredients" such as ICT tools used in assignments or guest lectures, you can get it neatly with Course diaries (instead of asking feedback e.g. in other course deliverables/assignment reports), as you can have them compiled in one place and also send the feedback forward to guest lecturers, which rarely get as much feedback via regular course feedback[.]

Teachers have reported very diverse technology use cases for Course Diaries. This is aligned with the diverse results from other dimensions of the questionnaire answers. Cognitive support is the most recommended technology use case. The tool is seen to be an effective tool for collecting actionable group-level data. In addition, the clear topic-based, typically also chronological, and systematic approach to deliver course content and reflect on that, is at the core of this type of tool, thus contributing to cognitive support. Only two teachers recommended the tool to combine cognitive and presentational support. Perhaps these should be highlighted when this type of tool is introduced to teachers.

\section{Discussion}

Prior empirical evidence has demonstrated the benefits of technology use in education. The positive effect of technology use has been shown to be the highest in feedback activities. Further, a combination 
Improvement of Teaching and Learning Experience by Online Course Diary Tool: ... Kivimaki et al.

of cognitive and presentational support has been suggested to be the most promising combination. Earlier research has also shown the positive and negative effects of the teacher-student relationship on school engagement and achievement. The current COVID-19 pandemic has created a burst of demand for timely feedback to inform adaptive teaching and to capture the emotional climate of a course. Teachers report that they are lacking the immediate feedback that could be received in lecture rooms and that Course Diaries delivers one solution for this problem.

Results of this study show that teachers aim to use Course Diaries for dynamic student online monitoring, preparing for instructional events, and that some teachers wish use it to promote deeper learning. In observed changes, teachers report seeing the results they were seeking. In addition, several teachers report thinking about teaching on the meta-level. Based on our results, there were no observed adverse effects on the regular feedback given after a course. Instead, teachers reported having positive effects on regular course feedback, e.g., better overall course assessments due to the teacher showing an interest towards student learning. Some teachers extended their view to a more extensive implementation of Course Diaries as a part of the university's regular feedback system. Indeed, activities that follow the structured learning diary model, such as Course Diaries, could be the modern solution for supporting the growing use of virtual platforms, in which we need effective methods for collecting timely feedback on the course's emotional climate and whether the students understand the topics being taught. In a typical lecture situation, an experienced teacher would trust their gut feeling and interpret body language and other indirect indications of students' emotional states. It is difficult to achieve this in teaching and instruction activities that occur entirely in online spaces.

Teachers' experiences with the structured learning diary tool shows promising results in engaging teachers in adaptive teaching and resulting in better course feedback. Some teachers use Course Diaries to foster their own personal growth. Some aim to execute deeper learning by incorporating Course Diaries as an integral part of their course, while others can use the tool to monitor the completion of simpel learning tasks. Overall, the results show that teachers have diverse aims using the diary method. The end results demonstrate diverse outcomes when using the tool. The implementation has resulted in almost entirely positive outcomes in summative course feedback. Finally, teachers recommend this kind of tool to be used as a cognitive support, which they see working for both teachers and students.

Teachers see the future use of Course Diaries to serve multiple technological purposes. The majority of the teachers recommended the tool for cognitive support. This is not surprising, considering the explicit day-to-day presence of all the course topics and interacting with them. Based on teachers' answers, these topics and summaries can further be used during the course to act as a discussion topic during a lecture. The fact that some teachers take a lighter touch with Course Diaries, i.e. using it to check whether an individual student watched a video link assigned by the teacher, suggests that the tool is easy to adopt and can be used to lighten a teacher's cognitive load. In their qualitative study on teachers' technology use during the COVID-19 pandemic, Adov and Mäeots (2021), divided their participants (teachers) into three groups and found that feedback was one of the shared technology use obstacles among all three groups. They found that the teachers were concerned that by technology use, they would not know whether their students have understood the taught topic and whether they need any additional support from the teacher. This can be one of the reasons behind the general positive adoption of the Course Diaries. Teachers are now missing the instant feedback of the face-to-face lectures. Course Diaries is giving them just that (or the nearest equivalent of that).

The results of this study are limited due to low number of teachers' answers. Conversely, the answer rate was good (58\%) and teachers in the sample are experienced teacher who had been using the Course Diaries and its earlier versions on several courses. The anonymic data collection method further empowers the evidence. In sum, the results should be viewed as explorative for further research design. The Course Diaries or similar approach should be tested in other learning environments and institutions in a larger scale. Here, the didactical design of each course, should be recorded and log data from the tool usage, e.g., the use of competence, difficulty, feeling and expectations in instructional design, should be connected to the analysis. Despite the limitations, this study contributes to expand our 
Improvement of Teaching and Learning Experience by Online Course Diary Tool: ... Kivimaki et al.

knowledge on teachers' readiness to adopt new type of feedback tools into their courses, and suggests positive results likely due to the freedom given to teachers in how they use the tool. Further, this study suggests increased training for teachers fully reveal the pedagogical potential of this type of tools.

\section{Conclusions}

We studied teachers' adoption of a learning analytics tool, Course Diaries. This structured learning diary tool is designed to record students' learning experiences during higher education institutions. Teachers' experience with the tool was collected through an anonym structured open response form with four questions related to (1) aims for the tool use, (2) noticed changes during instruction, (3) effect in regular course feedback, and (4) teachers' recommended situations for the future use of the tool. Teachers aimed to monitor their students, be better prepared for their own teaching, and promote deeper learning. Teachers reported getting insights from the course, which resulted in course content changes. Some teachers observed unplanned changes in how they thought about themselves as teachers. One reported noticing a similar change in students' thinking. No one reported adverse effects on regular course feedback content or answer rates. Teachers had been given free hands to use the tool, which resulted in a situation where some teachers had utilized the tool very diversely. In contrast, others only used it only for a limited purpose. Here, we suggest further training for teachers. In general, our results underline that teachers want to be aware of how their students are learning the instructed content. This knowledge gap is a highly topical question during the COVID-19 pandemic, where the rapid shift to online learning has left teachers in the dark, lacking this kind of instant feedback. Structured learning diary tools have the potential to reduce this feedback gap.

\section{References}

Adov, L., \& Mäeots, M. (2021). What Can We Learn about Science Teachers' Technology Use during the COVID-19 Pandemic? Education Sciences, 11(6), 255.

https://doi.org/10.3390/educsci11060255

Alrefaie, Z., Hassanien, M., \& Al-Hayani, A. (2020). Monitoring Online Learning During COVID-19 Pandemic; Suggested Online Learning Portfolio (COVID-19 OLP). MedEdPublish, 9(1), 110, https://doi.org/10.15694/mep.2020.000110.1.

Allison, D. (1998). Investigating learners' course diaries as explorations of language.Language Teaching Research, 2(1), 24-47. doi:http://dx.doi.org/10.1191/136216898666765145

Bartlett, R., \& Milligan, C. (2015). What is Diary Method?. : Bloomsbury Academic. Retrieved May 14, 2021, from http://dx.doi.org/10.5040/9781472572578

Borokhovski, E. F., Bernard, R. M., Tamim, R. M., \& Schmid, R. F. (2016). Technology integration in postsecondary education: A summary of findings from a set of related meta-analyses. Russian Psychological Journal, 13(4), 284-302.

Broadbent, J., Panadero, E., \& Fuller-Tyszkiewicz, M. (2020). Effects of mobile-app learning diaries vs online training on specific self-regulated learning components. Educational Technology Research and Development, 68(5), 2351-2372. https://doi.org/10.1007/s11423-020-09781-6

Dignath-van Ewijk, C., Fabriz, S., \& Büttner, G. (2015). Fostering self-regulated learning among students by means of an electronic learning diary : A training experiment. Journal of Cognitive Education and Psychology, 14(1), 77-97. Retrieved from https://www.proquest.com/scholarly- 
journals/fostering-self-regulated-learning-among-students/docview/1654889234/se2? accountid $=27468$

Geraldine, G., Schalk, A., Rooney, P., \& Lang, C. (2021). A Stakeholder Informed Professional Development Framework to Support Engagement with Learning Analytics. In LAK21: 11th International Learning Analytics and Knowledge Conference (LAK21), April 12-16, Irvine, CA, USA. Conference presentation.

Glaser, B., \& Strauss, A. (1967). The discovery of grounded theory. Strategies for qualitative research. Chicago, IL: Aldine.

Gronseth, P. W. (1999). Course Diary: A Valuable Information Source. The Mathematics Teacher, 92(6), 496-497.

Hahto, T. (2020). Student Experience of Mobile Dynamic Feedback System Application. Master's Thesis. Aalto University.

Kivimäki, V., Pesonen, J., Romanoff, J., Remes, H., \& Kauppinen, T. (2018). Supporting understanding of students' learning via visual self-assessment. EUNIS Annual Congress. Paris.

Kivimäki, V., Pesonen, J., Romanoff, J., Remes, H., \& Ihantola, P. (2019). Curricular Concept Maps as Structured Learning Diaries: Collecting data on self-regulated learning and conceptual thinking for learning analytics applications. Journal of Learning Analytics, 6(3), 106121. https://doi.org/10.18608/jla.2019.63.13.

Klug, J., Ogrin, S., Keller, S., Ihringer, A., \& Schmitz, B. (2011). A plea for self-regulated learning as a process: Modelling, measuring and intervening.Psychological Test and Assessment Modeling, 53(1), 51-72. Retrieved from https://www.proquest.com/scholarly-journals/plea-selfregulated-learning-as-process-modelling/docview/1399687086/se-2? accountid $=27468$

Pesonen, J., Ketola, E. E., Kivimäki, V., \& Ihantola, P. (2020). Does Using Structured Learning Diaries Affect Self-regulation or Study Engagement? An Experimental Study in Engineering Education. Conference proceedings - Frontiers in Education Conference (p. https://doi.org/10.1109/FIE44824.2020.9274163). Uppsala: IEEE.

Roorda, D., Koomen, H., Spilt, J., \& Oort, F. (2011). The Influence of Affective Teacher-Student Relationships on Students' School Engagement and Achievement: A Meta-Analytic Approach. Review of Educational Research, 81(4), 493-529.

https://doi.org/10.3102/0034654311421793 